\title{
Lapurdum
}

LAPURDUM Euskal ikerketen aldizkaria | Revue d'études basques |

Revista de estudios vascos | Basque studies review

$3 \mid 1998$

Numéro III

\section{Ternuaco Penac deitu idazkiaz zenbait ohar}

\section{Aurélie Arcocha-Scarcia}

URL : https://journals.openedition.org/lapurdum/1685

DOI : 10.4000/lapurdum. 1685

ISSN : 1965-0655

Éditeur

IKER

Édition imprimée

Date de publication : 1 octobre 1998

Pagination : 103-123

ISBN : 2-84127-152-8

ISSN : 1273-3830

\section{Référence électronique}

Aurélie Arcocha-Scarcia, «Ternuaco Penac deitu idazkiaz zenbait ohar», Lapurdum [Linean], 3 | 1998,

Sarean emana----an 01 septembre 2010, kontsultatu 23 février 2022. URL: http://

journals.openedition.org/lapurdum/1685; DOI: https://doi.org/10.4000/lapurdum.1685

IKER UMR5478 | Arcocha-Scarcia A. 


\section{A. ARKOTXA-SCARCIA}

\section{TERNUACO PENAC DEITU IDAZKIAZ ZENBAIT OHAR}

\section{Résumé - Quelques remarques sur le manuscrit Ternuaco Penac [Les peines de Terre-Neuve].}

Le manuscrit MS 97 du Musée Basque de Bayonne est constitué par un ensemble de textes poétiques d'origine diverse dont beaucoup sont anonymes et non datés. Le tout a dû être rassemblé entre la fin du XVIII ${ }^{e}$ et les toutes premières années du XIX siècle, puisque le carnet, outre la mention Quelques vers anciens et nouveaux, porte la date de 1798 et qu'à la fin de la Table des Matières (Aurkhibidea), figurent deux poèmes datés de 1802 et 1808, ce qui fait supposer l'intervention d'un autre copiste au plus tôt en 1808 .

Le carnet a été édité dans sa totalité pour la première fois en 1986 par P. Urkizu. Au sein de ce premier corpus, la trilogie formée par les trois textes consacrés au voyage des pêcheurs de Terre-Neuve occupe une place à part. Ces textes évoquent les conditions terribles du périple et du séjour, d'où le titre de la trilogie: Ternuaco penac.

Il convient, au préalable, de présenter le manuscrit en le situant dans un cadre historique allant de la fin du XVII à 1763 (Traité de Paris et fin de la Guerre de Sept Ans). Dans un second temps, une étude comparative des trois versions imprimées de ces dernières années (1986, 1987 et 1991) parues dans trois éditions, dont une bilingue basque/espagnol établie par G. Elortza en 1987, permet de mettre en lumière les variantes, tant il est vrai que ces versions ne sont pas identiques.

11 apparaît ainsi que les éditions de 1986 (A) et 1987 (B) présentent des différences (au niveau de la lecture et de la prise en compte des paratextes essentiellement) par rapport au texte d'origine $(0)$, une reproduction intégrale du manuscrit étant présentée pour la première fois dans sa totalité ici en annexe.

Seule cependant l'édition de 1991 (C) s'éloigne radicalement du texte originel, non seulement parce que le texte en a été modifié mais surtout par l'ampleur des carences constatées (strophes absentes ou amputées pour le premier texte de la trilogie) et la non prise en compte de la version Elortza parue en 1987 dans Itsasoa III, par exemple.

Ternuaco Penac deitu idazkia 1986-an P. Urkizuk lehen aldikotz argitaratu' zuen Baionako Erakustokian dagoen eskuz ixkiriatu kantu bilduma osoarekin batera. G. Elortzak ere, 1987an argitaratu zuen, gaztelerara itzulia, Itsasoa II ${ }^{2}$ 
liburuan. Biek azpimarratzen dute J. Haritschelhar orduko euskal erakustokiko zuzendariari nola M. de la Sotak 1966an eman liburutegian zagon bilduma hori. J. Haritschelharren ustez, oraikoan dugun kantu bilduma zaharrena :

"Liburu honetan [P. Urkizuren edizioaz mintzo da] argitaratzen den kantu bilduma, nik dakidanez bederen, daukagun zaharrena da, XVIII. mendearen azken urtetakoa, 1798 koa. Hala salatzen dauku tituluak diolarik aurkitzen direla bertsu zahar cta berriak. Gehienak ez ezagunak dira, iparraldekoak noski.

Esku izkribua Baionako Euskal erakustokian dago Manu de la Sota-ren ganik etorria..." 3

Bizkitartean, eskuizkribuaren aipatzeko orenean ezberdintasun batzu agertzen dira bi ikerlarien artean. Biek karnetaren neurri ezberdinak ematen dizkigute, adibidez:

"Museoko eskuizkribu honek $155 \mathrm{~mm} . \times 110 \mathrm{~mm}$. neurtzen dituen liburuska bat osatzen du." (G. Elortza. 1987, 277)

"Ehun eta hamaika orrialdedun liburutto honen neurriak $107 \mathrm{~mm}$. zabalera eta 154 mm. luzera dira." (P. Urkizu. 1986, 15)

Halaber, Baionako kahierrean den koplen kopuruaz ez daude arras bat :

"Ternuako bertso-saila bakartzat hartuz gero, 29 poema ditugu, baina hiru direla kontsideraturik', 31 ateratzen dira." (Elortza. 1987, 279)

P. Urkizuk, berriz, G. Elortzak aipatzen ez duen Aurkhibideaz zerbait dio baina ez du hau bere liburuan agertzen; ez du ere azaltzen zertako Aurkhibidean 27 kopla agertzen diren eta berak agertzen duen edizioan, berriz, 29:

"Aurkibide bat ere badu 98. orrialdean 27 poemen zerrendarekin."

Horiek horrela direla eta, testu horiei behako bat eman diezaiegun ikusteko, lehenik, zertako Ternuaco Penac izenburupean ezar daitezkeen hiru itsasoko kantu ezberdin (bakar batek baitakar Ternuaco Penac izenburua) ; bigarren, gorago aipatu 1986, 1987ko bertsio inprimatuen konparaketa eginez, bi argitalpen horien arteko ezberdintasunak zein diren ikusteko, gehituko diegularik 199 lean agertu Bertsolaritzaren Historia- $I$-, itsasoko kantu horietaz liburu honetan atera den azken bertsioa eztabaidagarria baita arras.

\section{1 - Idazkia :}

\section{1-a : Aukhibideaz :}

Urrunago joan baino lehen, ikus ditzagun, zehazkiago, aipatu kantuak eta azal dezagun zertako hirukote/trilogia bat osatzen duten.

Jadanik erran bezala, hiru dira aztergai ditugun idazkiak ${ }^{5}$ : lehenik, Partiada tristea, Ternuara, zortzi silabako 20 laukoz $(\mathrm{A} / \mathrm{A} / \mathrm{B} / \mathrm{B} /)$ osatzen dena, bigarrenik, Itsassoco Perillac, hau ere zortzi silabako 20 laukoz (A/A/B/B/) eraikia, eta, azkenik, Ternuaco Penac, zortzi silabako 13 laukoz (A/A/B/B/) $)^{6}$.

Bildumaren arkitekturak berak ematen ote digu hiru kantu horien elkartzeko arrazoirik? 
Gogoaraz dezagun, lehen, G. Elortzak diona :

"Hiru poemok bakarrean nahiz batera irakur daitezke, bakoitzak osotasun aski baitdauka eta hiruren artean batasun sendoa osatzen dute." (G. Elortza. 1987, 278)

Bizkitartean, batasun hori, itsasoko kantu horien kopiatzaileak berak finkatzen du Aurkhibidean hiru kantuak izenburu bakar baten pean ezarriz. Ohar gaitezke, gainera, Aukhibidean eta bildumaren barnean diren izenburuen artean aldakuntza ortografikoak badaudela', eta ere ezberdintasunak, zenbait aldiz aldatzen baitira ${ }^{8}$ ere, etab.

Hona Ternuaco Penac nola agertzen den bilduman dagon Aurkhibidean :

"Gaucen Aurkhibidea/Ternuaco penac, depuis le jusqua lle"

\section{1-b : Idazteko garaiaz egin daitezkeen gogoctak :}

Kantu horiek behin eta berriz kopiatuak izan daitezke eta, behar bada XVII. mendekoak dira, gisa guziz ez preseski XVIII. mende ondarrekoak bildumak dakarren 1798 urteari fidatuz. Horretarako hiru arrazoi : lehena, ikustea bilduman badirela 1798a baino aise lehenagoko kantuak, adibidez, Louis XIV-ari eskainia dena haren heriotza (1715) baino lehenago idatzia izana da, gero, Aurkhibidean bigarrenik kokatzen den, Çarranţ̧aco Penac idazkian Ternuako Plazentzara heltzea aipatzen denez, nahi ta ez 1713a baino lehenagokoa da hau ere :

"Aphirillac cituen justu hemeretci

noiz ere haiquinduen zundaz ardietsi,

bazco egun handian guinduen atheratu,

biaramunean Placenţ̧an barnan sartu." (URKIZU 1986, 105)

Azkenik, kantu horietan den giroa ez da batere ere bildumak dakarren Ternuaren premia. Franchisaren caltea Laphurdin ${ }^{10}$ idazkian dagona, gogoan ukanez kantu hau 1790/91 urteetakoa dela, urtemuga hau baitzaio gehitua:

"Goïzportuac" khorrocan, Sn Pierrac'2 herren,

Belilla ${ }^{13}$ candelan da bai eta hil hurren;

costatarrac beçala Laphurdi gucia

franchisaren azpian datça ehortcia." ${ }^{14}$

Ez dezagun ahantz halere, 1713ko Utrechteko hitzarmena aitzin, XVII. mende bukaerako urteak ez zirela batere bakezkoak izan Ternuan, bereziki Ingeles eta Frantsesen artean : 1600ean Plazentza (Placentça, Plaçentça Detcheverryrentzat, gaur Placentia) Ingelesek xehatu zuten, 1696an Frantsesek Ingelesei berriz hartu... 1713ko Utrechteko tratatuaren ondotik egoera aldatu zen, baina Frantsesendako kalteak handiak izan baziren (ikus E. Ducéréls), zer erranik ez erresuma espainolean ziren Gipuzkoa eta Bizkaiarendako.

Urrunago joan gabe azpimarratu behar da Utrechteko hitzarmena aitzin Lapurdi, Gipuzkoa eta Bizkaiak beren bi gobernuen bitartez cunversa frango muntatu zituztela harreman komertzialen onetan ; erran beharra dago ere borroka anitz bazela batzutan bi alderdietako marinelen artean (gogora Hendaia eta Hondarribiaren artekoak, adibidez) baina, denen onetan eginak ziren hitzarmen 
premiatsu horien berritze eta irauntaraztea oinarrizkoa zen itsas bazterreko jendeentzat eta iraun zezaketen batzutan Espainia eta Frantziaren arteko gerlen gainetik:

"Una tradición documentada muy antigua", dio M. Ciriquain Gaiztiarrok "abonó que tanto la una (la provincia de Guipúzcoa) como la otra (el señorio de Vizcaya) negociaran tratados de concordia-"conversas", se les llamaba asi en los documentos-, con la provincia francesa de Labort, debidamente autorizados por las Coronas, aunque sus paises estuvieran en guerra, entre ellos, lo que les permitió mantener relaciones comerciales para su mantenimiento en medio del fragor de las lombardas y los cañones. Fueron muchas las concordias celebradas, al efecto, a través del tiempo. Durante la guerra mantenida entre España y Francia, después de la Liga de Augsburgo (1686), los guipuzcoanos y los viscainos disfrutaban de una de estas concordias con los labortanos, aunque los franceses se dispusieran a invadir Cataluña."

Bizkitartean, 1690ean, Espainiako gobernuari ez zitzaion iduri Gipuzkoa eta Bizkaikoek conversa errespetatu behar zutela:

"...haberse servido S.M. prohibir, por ahora la concordia o conversa que en otras ocasiones de guerra permitía ajustar con la provincia de Labort."16

Halere goiti behera batzu barne, conversa, oro har, atxikitzen da ${ }^{17}, 1693$ ko Bergarako Junta Generalek diotelarik :

"Habiendo conferido largamente todo lo que por disposicion de la N. y L. villa de Azpeitia se ha discutido entre los Caballeros Comisarios de V.S. y los del Señorió de Vizcaya, sobre las necesidades que padecen los naturales y habitadores de ambas provincias, por la suspensión de la Concordia que con el permiso de S.M. suele asentarse y practicarse entre V.S. y la provincia de Labort, en Francia, para la comunicación reciproca de frutos de ésta y aquella provincia, y para la seguridad de todas las embarcaciones de ellas en sus navegaciones (...)"'1s

Eta Juntek berriz eskatzen dute conversa :

"que como entre provincias tan principales y tan empeñadas con los vínculos de parentesco y amistad, siempre han profesado V.S. y el Señorio de Vizcaya, y que en disposición tiene resuelto la Diputación del Señorio, se solicite con grande esfuerzo el beneplácito de S.M. para que se sirva de conceder a ambas Provincias el uso de la Concordia que, en las ocasiones antecedentes de la actual guerra se ha permitido con los Labortanos (como precisa para el sustento y conservación de los Naturales de V.S. y del Señorio) y que para su mayor y mejor efecto conviene vayan a la Corte dos Caballeros uno de cada parte, que con instante y eficaz súplica obtengan esta gracia de S.M. en nombre y con representación de ambas provincias." ${ }^{19}$

Juntek eskatzen zutena lortu zen, 1694ean Baionako kapitain merkatariek izenpetu dokumentua hor dugu lekuko (et de prendre"des Espagnols quils jugeront à propos de mélér parmi leurs Equipages" ${ }^{20}$ eta ere 1695eko Mutrikuko agiri bat :

“...la ciudad de San Sebastián pidió a la Junta cartas a favor para la ciudad de bayona, pronvincia de Labort, y Duque de Agramont, para que se concediese 
libertad a los dos navios de dicha ciudad apresados por una fragata francesa que al presente se hallan en el puerto de Nantes, La Provincia se las concedió. ${ }^{21}$

Halere, 1696 eta bereziki 1697 tik goiti Ternuan zaila izanen da Gipuzkoar eta Bizkaitarrendako arrantzako lanetan bakean ibiltzea. 1697ko urtarrilaren 30ean Versaillesen idatzi nota batek dio kolonia frantsesarenak diren portuetan kanpotarrek ez dutela libro arrantzan ibiltzea, Frantziako erregek espainol untzi batzu Plazentzako bazterretan bazebiltzela jakin zuelakotz. Notak pasarte batean $\mathrm{dio}^{22}$ :

"Los españoles se hallan asi imposibilitados para continúar con la navegación en Terranova porque sólo se dejan libres los puertos de la Canal y el pasar por éstos se consigue pocas veces porque la entrada de la Canal muchas veces se ha hallado de bancos de nieve y otras veces se la pesca por el largo pasaje y como se dice precuando (?) del recurso de poder volver a los puertos de Sta Mariá y Sn Lorenzo y otros que están a poca distancia de Placencia, será muy factible que un navio, de cuatro viajes no logre uno, como lo saben todos los franceses."'s

Baina Gipuzkoako marinelek ez zuten trenpea galdu ; kapitain eta bandera frantsesarekin joaten ziren 1698/99 eta 1705ko dokumentu batzuk dioten bezala, "turkoetaz" beldur zirela :

“... el navio San Juan Bautista perteneciente a don Domingo Pérez de Isaba, difunto, vecino que fue de esta ciudad y a otros naturales de ella, siendo su capitán Domingo de Mirandola, salió del puerto de esta ciudad para su viaje a Terranova, a la pesquería del bacallao, por el mes de Abril de año 1705 llevando por precaución de los turcos capitán de la bandera francesa' ${ }^{124}$

Ultrechteko hitzarmenak egoera zailago bihurrarazi zuen. Baina Frantziak, urte andana batzuendako baldin bazen ere, Ingalaterrarekin antolamendu bat atxeman zuen Ternuako itsasbazterretan egiten zen arrantzaz. Ingalaterrak Ternuako ekialde eta hegoaldeko eremuak arras zaintzen baldin bazituen ere, Frantsesak (eta beraz Lapurdikoak) sartaldean bazebiltzen, 1713 baino berantagoko Joanis de Hiribarrenen kartak erakusten duen bezala ${ }^{25}$. Gipuzkoa eta Bizkaitarrentzat berriz, kaltea ikaragarria izan zen jadanik 1713 an ez baitzuten deus ateratzen ahal izan hitzarmen horretarik. ${ }^{26}$

Erran beharra dago 27 urte geroago berriz piztu zela gerla Ingeles eta Frantsesen artean Aix-la-Chapelleko hitzarmenarekin bururatuz; ondotik, 1756an Zazpi Urteko gerla hasten da bi partaideen artean eta 1763an gelditzen Pariseko hitzarmenarekin : Frantziak Ipar Ameriketako lurralde guztiak galtzen dituelarik salbu St Pierre eta Miquelon ${ }^{27}$.

Erran gabe doa Lapurdiko portuek jasanen zituztela ondorio gaitzak.

Utrechteko hitzarmenaren ondotik bakailoaren arrantzak sekulako beherakada ezagutu zuen Donibane Lohitzune eta Baionako portuetan : 1635ean Donibane Lohitzunen 80 bakailoaren arrantzako untzi baldin baziren, 1716an bakarrik 11 gelditzen ziren...Halere, 1738an badira oraino 18 eta 1786an Baiona eta Donibane Lohizun 40 bakailoa-untzitara heltzen dira ${ }^{28}$.

Ternuako itsasaldeak ezin hobeak baitziren bakailoaren arrantzarendako, bereziki hegoaldean ziren hiru "Banc" edo "Banck"ak deituak ziren lekuak, han bakailoa-sarda handiak baitziren : Banck of the Islands, St Pierre eta Miquelonen 
itsas zabalean, Verte Banck (Banc à Vert) Plazentzaren hegoaldean den itsas zabalean eta Main Banck (Le Grand Banc), guti gora behera Cap d'Arras (Cap de Raze, de Ras eta gaur Cape Race) -etik Cap St Fruriçois-ra (gaur Cape Saint Francis) den lurraldearen itsas zabalean, han aurki baitzitekeen bakailao-sarda handiena ${ }^{29}$.

Termuaco Penac-etan agertzen den egoera, dirudienez 1713ko urtea baino lehenagokoa da, gerla aipurik ez da, Ingelesak, adibidez ez dira aipatzen, bai ordea Isquimaüac ; halere, oraikoan ${ }^{30}$, ez daiteke deus behin betikorik erran, 1713 eta 1763a artean idatzia baitaiteke ere.

\section{2- Idazkiaz egin izan diren agerketa inprimatuen konparaketa :}

Gogora dezagun hemen aipatuko diren agerketak hiru direla A, B, C hizkiekin izendatuko direnak : A : 1986koa (P. URKIZU : Bertso zahar eta berri 1798), B : $1987 \mathrm{koa}$ (G. ELORTZA, Itsasoa IIIn.), eta C : 199Iekoa (J. GARTZIA. P. URKIZU, Bertsolaritzaren Historia, Lapurdi, Baxanabarre eta Zuberoako bertso eta kantak, I Anonimoak).

Jatorrizko eskuzko idazkiari O ezarriko zaio O1 (Partiada tristea, Ternuara), $\mathrm{O} 2$ (Itsassoco Perillac) eta O3 (Ternuaco Penac) hiru kantuen izendatzeko erabiliko direlarik.

Irakurleak berak beha dezan, eranskinetan gehituko da jatorrizko eskuizkribua M. de la Sotak Baionako Euskal Erakustokiari (Musée Basque) emana ${ }^{31}$; agerketa inprimatuen xehetasunak, berriz, bibliografian emanak izanen dira.

\section{2-a : Bertso edo koplen kondatzeko moldeaz:}

$\mathrm{O}$

$\mathrm{O} 1=20$ bertsu

$\mathrm{O} 2=20$ bertsu

$\mathrm{O} 3=13$ berstu,

kopiatzaileak

eskuz gehitzen

ditu zenbakiak.
A

$\mathrm{O} 1+\mathrm{O} 2+03$

53

bertsu
$\mathrm{B}$

$\mathrm{O} 1+\mathrm{O} 2+\mathrm{O} 3$
$=$
209
neurtitz

$\mathrm{C}$<smiles>[O+2][18O]</smiles>

53 (LIII)

bertsu

\section{2-b : Kantuen agertzeko moldeaz:}

Jakiteko zein bertsutan diren aldakuntzak, izendatzeko molde hau hautatuko da : 02-4 (erran nahi da Itsassoco Perillac-en 4.bertsua); A24 (erran nahi da 1986ko Bertso zahar eta berrin 24. bezala agertzen den bertsua); B93 (1987ko Itsasoa IIIn 93. neurtitzaren zenbakiarekin agertzen den bertsua); C24 (ikus A24).

- O1 : Ohar gaitezke hastapeneko izenburua Partiada tristea bakarrik zela eta gero bertze esku batek gehitu zuela Ternuara (A, B eta C agerkarietan ez da hori aipatzen). Ikus dezakegu ere Olen tituluaren azpian A. dagola (gero, bilduman Ternuaco Penac hirukotearen ondotik heldu den çarrantçaco penac kantuaren azpian B. ezarriko duelarik kopiatzaileak). Seinale horiek azpimarratzen dute 
kopiatzaileak hiru kantuek duten batasuna azpimarratu nahi izan zuela, B rekin bertze sail bati hastea emanez.

\section{2-c: Agerketa inprimatuetan diren ezberdintasunetaz :}

\begin{tabular}{|c|c|c|c|}
\hline $\mathrm{O}$ & A & $\mathrm{B}$ & $\mathrm{C}$ \\
\hline $\begin{array}{l}\text { OI-14 : "Jaunac } \\
\text { diçula gracia" }\end{array}$ & $\begin{array}{l}\text { A 14: "Jaunac diçula } \\
\text { gracia" }\end{array}$ & $\begin{array}{l}\text { B53: "Jaunac digula } \\
\text { gracia" }\end{array}$ & $\begin{array}{l}\text { CXIV : "Jaunak dizula } \\
\text { grazia" }\end{array}$ \\
\hline $\begin{array}{l}\text { O -19: "maiñada } \\
\text { haz çaizte onac" }\end{array}$ & $\begin{array}{l}\text { A } 19 \text { : "Maiñada, } \\
\text { haz çaizte onac" }\end{array}$ & $\begin{array}{l}\text { B73: "maiñada haz } \\
\text { çaike onac (?)" }\end{array}$ & $\begin{array}{l}\text { CXIX : "Mainada, haz } \\
\text { zaizte onak" }\end{array}$ \\
\hline $\mathrm{O} 2$ (titulua) & A21 (titulua) : & B81 (titulua) & $\mathrm{C}$ XXI (titulua): \\
\hline "Itsassoco Perillac" & "Itsasooco Perillac" & "Itsassoco Perillac" & Itsasoko Perilak \\
\hline $\begin{array}{l}\mathrm{O} 2-4 \text { : "beguiz ecin } \\
\text { ikhus Larrun" }\end{array}$ & $\begin{array}{l}\text { A24 : "Beguiz cein } \\
\text { ikhus Larrun." }\end{array}$ & $\begin{array}{l}\text { B93 : "beguiz ecin } \\
\text { ikhus Larrun." }\end{array}$ & $\begin{array}{l}\text { CXXIV: "Begiz zein } \\
\text { ikus Larrun." }\end{array}$ \\
\hline $\begin{array}{l}\text { O3-12:"triste errain } \\
\text { eroria :" }\end{array}$ & $\begin{array}{l}\text { A52 : "Triste, errain } \\
\text { croria," }\end{array}$ & $\begin{array}{l}\text { B205: "triste bezain (?) } \\
\text { Eroria ;" }\end{array}$ & $\begin{array}{l}\text { CLII : "Triste errain } \\
\text { eroria," } " \text { "32 }\end{array}$ \\
\hline
\end{tabular}

\section{2-d: C agerketan diren aldaketak eta hutsetaz:}

C agerketan (Bertsolaritzaren Historian (1991)) kantuetaz egiten den bertsioa ez da bakarrik jatorrizko testutik gehienik urruntzen dena baina ere Ol (Partiada Tristea, Ternuara) arras ondatzen eta itxuraz aldarazten duena.

Ortografia oraikotzen denez, "c"-ak, "k" bilakatzen dira, adibidez, baina, denbora berean : "Perillac", Perilac", eta "gilla", "gila", bi etsenplutan gelditzeko; era berean, "Mariñelen", "Marinelen" bihurtzen da eta, beti hor gelditzeko, "maiñadac", "mainadac"... Kontsonanteen gibeletik diren "h"ak ere desagertzen dira, "senhar"-ek, "senar" ematen duelarik..

O1-2 -ren lehen neurtitza : "Churi garbi ceru gaiña", "Txuri garbi zeru gaina," (CII), bilakatzen da, era berean Ol-10-en lehen neurtitzean den "chumea", hitza, "xumea" idazten delarik...

O2-3-ren lehen neurtitza : "Itsasoaren gañean", itsasoaren gainean" (CXXIII) bilakatzen da.

Baina, erran bezala, ezin sinetsia da ikustea zer bilakatzen den O1 Partiada tristea, Ternuara-ren hastapena $\mathrm{C}$ agerkarian :

- hirugarren kopla "Untcitic artilleria/..." falta da...

-laugarrena hirugarrenaren lekuan aurkitzen da eta gainera hirugarrenaren bi azken neurtitzekin...

Ternuaco Penac idazkiarekin egin den 199 leko agerketa inprimatuak argi eta garbi aitzinatze baten orde, gibelatze bat izan dela salatzen du, halaber, ikus dezakegu A eta B direla jatorrizko testutik hurbilenik ibiltzen direnak. Halere, azken bi agerketa hauetan, zenbait gauza ez dira beti agertzen. Barratuak diren pasarteak, adibidez, zenbaitetan seinalatzen dira eta bertze zenbaitetan ez (Ak eta Bk 
ez dute agertzen Ol-10ean "Adios"-en azken silaba barratua dela eta ondorioz "Adi" agertzen dela bakarrik, gauza berdina gertatzen delarik O1-1 lean). Aldiz A agerketan nota batean agertzen da (ikus A39) O2-19an lehendabiziko bi neurtitzen erdiak barratuak direla: "ez du deus pausuric" dago ezabaturic" eta "loth toquiric" dago ezabaturik" (URKIZU 1986, 99).

Agian, lasterrezko ikuspegi honen bitartez ikus daiteke eskuz idatziak diren idazkien transkribatzea beti ahal bezein zehazki egin behar litekeela, berdin gertatzen delarik edizio agorn edo aspaldiko aldizkarietan sakabanatuak diren idazki inprimatuak berrinprimatzen direlarik.

\author{
A. ARKOTXA-SCARCIA \\ Bordeaux III, UPRESA 5478 - CNRS
}




\section{BIBLIOGRAFIA :}

CIRIQUAIN GAZTIARRO M. : Los vascos en la pesca de la ballena. Biblioteca de los Autores Vascos, E.V., San Sebastian 1979

CARTIER Jacques: Relations. (1534-tik 1542-ra. Édition critique par Michel BIDEAUX. Les Presses de l'Universiré de Montréal, Montréal, 1986.

DEGROS (Mme Maxime) : "La Grande Pêche Basque des Origines à la fin du XVIIle siècle", in Bulletin de la Société des Sciences Letres et Arts de Bayonne $\mathrm{n}^{\circ} 48$ (avril-juin 1944), n49 (juilletdécembre 1944) et $n^{\circ} 50$ (janvier - octobre 1945).

DUCÉRÉ Émile. : La pêche de la morue el la découverte de terre-Neuve par les Basques et les Bayonnais, Imprimerie - Stéréotypie, Garet, Pau 1893 (extrait du Bulletin de la Société des Sciences. Lettres et Arts de Pau, $2^{*}$ série, Torne XXII, 1892-1893).

EGAÑA - GOYA Miren : 'XVI eta XVII mendeetako Canadako Ternua eta Labrador-eko euskal lekuizenen zenbait berri “, in Anuario de Eusko-Folklore, Eusko Kkaskuntza, Tomo 32, 1984

- "Les toponymes basques au Québec", in Naturaliste Conadien, Hydro-Québuc, 1995

- "Dans le sillage des morutiers basques du Moyen Âge : une perspective sur l'origine et la définition du mot bacallao", (en collaboration avec Brad Loewen), in L'aventure maritime du golfe de Gascogne à Terre-Neuve. Éd. C.T.H.S., Panis, 1995.

ELORTZA Gerardo : "Ternuako ohiartzuna euskal olerki gintzan", in /tsasoa /I/, Etor, Donostia, San Sebastian, 1987.

GARZIA Joxerra, URKIZU Patri : Bertsolaritzaren Historia, Lapurdi, Baxanabarre eta Zuberoako bertso eta kantak, L, Anonimoak, Etor, Donostia 1991

GOYENECHE Eugène : Le Pays basque. Soule, Labourd, Basse-Navarre, Société Nouvelle d'Édition Régionale, Pau 1979.

HOYARSABAL Martin (Capitaine) : Les voyages avantureux du capitaine Martin de Hoyarsabal, habitant de çubiburu. Contenant les Reigles \& enfeignemens neceffaires à la bonne \& Seure Nauigation. A Bovrdeaux. Par Gvillavme Millanges, Imprimeur ordinaire du Roy. M. DC. XXXIII. (Hau hirugarren argitalpena da, lehına, Bordelen, 1579-an, egin zelarik).

HOYARZABAL Martin/DETCHEVERRY Piarres (Dorre) : Liburuhauda Jxasoco Nabigacionea. Marlin de Hoyarzabalec egiña Francezes Eta Piarres Detcheverry edo Dorrec efcararat emana. Eta cerbait guehiago abançatuba. Bayonan. Fauvet, Imprimerian Carmeffețco aldean DC. LX-X V II.

Edición facsimil de 350 ejemplares, Txertoa reprints, San Sebastián, 1985.

HUXLEY-BARKHAM Selma : "Los vascos y las pesquerias transatlánticas, 1517-1713", in Itsasoa III. Etor, Donostia-San Sebastián, 1987.

- The Basque Coast of Newfoundland. Great Northern Peninsula Development Corporation, 1989. m

LAHONTAN : Euvres complètes. [1702 eta 1703 artean]. Édition critique établie par Réal OUELLET avec la collaboration d'Alain BEAULIEU. Les Presses de l'Université de Montréal, Montréal, 1990.

PONTET Josette : "Les équipages des corsaires bayonnais au XVIII" siècle" in L'aventure maritime du golfe de Gascogne à Terre-Neuve. Éd. C.T.H.S., Paris, 1995.

URKIZU Patri : Bertso zahar eta berri zenbaiten bilduma (1798), Durangoko udala, Durango, 1987.

URQUIJO (Julio de) : "Versos al Dr. Ducos.", in R.I.E.V.XV (enero-mayo 1923).

- "El vascuence de San Juan de Luz", in R.I.E.V. XIV (abril-junio 1924). 


\section{Notak}

\section{P. URKLZU : Bertso zahar eta berri (1798). Durango 1986.}

2. G. ELORTZA : "Ternuako arrantzaren oihartzuna euskal bertsogintzan.", in, Itsasoa III, 1987, 277 286. Autoreak liburu horretan berean agerrarazten du ere kahierrean dagon bertze kantu bat: Ternuaren premia. Franchisaren caltea laphurdin, vers 1790 ou 91. Hau J. Urquijok RIEVen 1924ean lehen aldikotz argitaratua eta Joanes Etcheberri Ziburukoaren baleazaleen otoitzetan cragunenak diren pasarteak.

\section{J. HARITSCHELHAR in P. URKIZU : Bertso zahar eta berri zenbaiten bilduma (1748)...}

4. G. ELORTZAK gogoarazten du trilogia bat dagola Ternuari buruz Baionako 1798 ko kahierrean. Hiru kantu horiek direlarik: Partiada Tristea Ternuara, Itsassoco Perillac eta Temuaco Penac.

5. Ikus 4. nota.

6. Eskuizkribuak erakusten duen bezala, kantu honen azken bertsuaren ondotik norbaitek gehitu du "I3", bertsu kopuruaren gehiketaren finkat/:ko, gainerakoen bururapenetan " 20 " pertsona berak gehitu duen bezala. Ikus eranskinean emana den jatorrizkoaren fokokopia.

7. Adibidez, kahierraren barnean aurkikzen den şarranţ̧aco penac kantua, Aurkibidean Zarranzaco penac bezala idatzia ikusten da.

\section{Adibidez, Ste Rose, Bouquet à Me Zuturnahar. Aurkibidean Sa. Rosa, Zuaznabar, agertzen da.}

9. 1713.ko Utrechteko tratatuaren ondolik Ingelesen eskuetan gelditzen da Plazentza. Mugaren bi aldetako euskaldunak, erran nahi da Lapurdi Gipuzkoa, Bizkaiakoek (nahiz hauek neurri guttiago batekin) aspalditik Temua hegoaldeko eremu haietara joateko ohidura zuten eta han aurkitzen ditugu. Baina XVII. eko azken urteetako idazki batek erakusten du zer giro zen Plazentzan hamazazpi urte lehenago, ikusiko denez, gero eta zailago zen Plazentzan bakean bizitzea. Idazkia XIX. mendean kopiatu zen.

Jatorrizkol694ko dokumentuak kondatzen du nola zortzi merkatari (sei Baionakoak, bi Donibane Lohitzunekoak) eta lau Donibane eta Zibunuko kapitain erregeren notarioaren aitzinean presentatu diren Louis XIV. ak eskaintzen zizkien abantailak eta zituzien eginbeharrak zein ziren ofizializatuak izan zitezen kontratuaren bidez; XIX. mendean erantsi zen notak zioenez hamabi kapitainak ("dont six de Bayonne commerçants, et six de St Jean de Luz, et Ciboure) Plazentzako herriaren laguntzera baitzihoazen ("pour rovitailler la colonie de Plaisance"). 1694.ko otsailaren 16ko idazkiak hastapenetik, kapitainen izenak eman eta gero azpimarratzen du hauen engaiamendua :

"qui se sont engagé à porter à la colonie de Plaisance les secours de vivres, et munitions nécessaires pour la subsistance de la dite colonie. Les dits truitants s'obligent de payer au gouverneur et à l'Etat Major de la Garnison du dit Plaisance leurs appointements soit en argent effectif, soit en munitions ou vivres (...). Ils lèveront à leurs dépens, une recrue de 40. Bons Soldats qu'ils passeront au dit Plaisance, et leur payeront leur solde d'une année soit en vivres soit en habits (...).

Moyennant les quels offres et conditions S.M. Leur fournira au port de Rochefort, une de ses frégates de 30 a 36 pièces de canons pour user d'armes (...) et aparaux et munitions de guerre, tant pour l'armement que pour la rechange, bien carennée et pretle à mettre à la voile et une flutte au Port de Bayonne armée de 20 canons et pareillement pourvue de toutes les munitions et agrès nécessaires pour sa navigation des quelles frégattes et fluttes (...).

S.M. leur permettra pareillement d'armer à leurs dépens deux autres flutles à eux apartenants pour aller faire la pêche ou la troque au dit Plaisance ainsi qu'ils aviseront bon être, et leur fournira des Commissions en Guerre, pour les Capitaines qu'ils mettront sur les dites frégattes et fluttes.

S.M.leur permettra pareillement de lever par préférence les équipages des dites 4 fluttes dans le département de Bavonne de matelots qui ont été l'année 1693. à son service, et des invalides et de prendre des Espagnolls quils jugeront à propos de mélér parmis leurs Equipages, pour épargner les matelots qui doivent servir sur l'armée navale pendant la prèsente année.

En cas qu'en allant pendant leur séjour, où à leur retour du dit Plaisance, les dits 4 vaisseaux fassent quelques prises sur les ennemis de l'Etat, les dites prises seront entièrement au profit des dits traitans, sans que S.M. puisse y pretendre.

Et d'autant que les dits traitans payeront et nourriront à leurs dépens tous les Equipages des dits 4 Batimens, ils auront une pleine et entière liberté d'en disposer pour leur péche course où autrement ainsi qu'ils aviseront bon ètre pour le bien de leurs affiaires sans que le Gouverneur du dit Plaisance, où autres officiers en puissent aucunement disposer, S.M. leur permettant de rester au dit Plaisance tant qu'ils crvi- 
seront bon être pour le bien de leurs affaire (sic), et de charger à leur Retour, toutes les morues, huilles et autres marchandises qu'ils auront et de faire leur retour dans tel Port de France qu'ils aviseront bon être, à la charge de remettre à Rochefont où à Bayonne les dites frégattes et fluttes de S.M. sauf les risques, perils et fortunes de la mer et de la Guerre (...)."(Baionako Liburutegi Munizipaleko 285 zenbakia duen artxiboa)

Idazki interesante honen bitartez ikus dezakegu, lehenik, nola XVII. ondarrean untziak bakailoaren arrantzan (trukea ahantzi gabe) eta L. XIV. arendako kursan badabiltzala, Estaduaren politika eta lekukoen grina komertzialak kasu honetan ongi ezkontzen direlarik ( $\mathrm{cz}$ baitzen beti hala) eta bigarren, aipatuak diren "Espagnoll"etan gehienak mugaz bertzaldeko euskaldunak daitezkeela, nahiz ez menturaz denak, gogoan ukanez 63 bat urte geroago, 1757 an zer gertatzen zen Baionako Le Constant untziarekin : "...purmi les volontaires figurent quelques étrangers. Les mieux représentés étaient naturellement et de très loin les Espagnols : ils formaient à eux seuls plus de 90/100 de ce groupe : parmi eus une majotitḱ venait du Guipucoa ou de Biscaye, mais on comple une bonne proportion venue de toule le péninsule : de Jaca Séville, Cadix. comme de Cantabrique..." (J. PONTET, in CTHS, 1995, 407or.);

Giroa Plazentzan lanjerosa zen eta Ingelesen atakeak ardura gertatzen ziren. Plazentzan ari zen DETCHEVERRI "DORRE" bere karten egiten 1689an, bortz urte lehenago: "La generacion de Detcheverry" dio S. BARKHAMek "a finales del siglo XVII, era una de la ullimas en gozar de un campo abierto en Terranova. Ya los dos grandes imperialistas, Francia y Gran Bretaña, batallaban entre si por la supremacia de América del Norte (...)."

Baina ikusten da ere Plazentzan garai haietan mugimendu anitz bazela : "Placencia era el lugar donde se reunian corsarios, donde mercaderes de Boston vendian viluallas, bebida (...)." (S. BARKHAM in Itsasoa III, 713)

10. Titulu bau J. de URQUIJOk, LARRALDE medikuaren kahierretik hartua du, kantu osoa bezala "En la lista de alcaldes (maires) de San Juan de Luz, figura el "Ducos" que nos interesa por haber ejercido dicho cargo los años $1790-91$ y el año $\mathrm{K}$. Al mismo personaje se refieren los siguientes' versos que tomo del cuaderno del Dr Larralde.", in "Versos al Dr. Ducos", RIEV XV, enero-mayo 1923

P. URKIZUren edizioan, bertsu berak Ducos jaunaren laudorioac izenarekin agertzen dira, gehi nota bat "Vers 1790 ou 91. Ternuaren premia. Franchisaren caltea Laphurdin dio eskuizkiribuak goi eta behealdean.", in op. cit. 147-149.

12. Sn Pierrac gaurko St Pierre eta Miquelon irlak daitezke, erran nahi da Temuako mendebal-hegoan direnak); horrela dio DORREk : Seguidandire Temuago graduac./ (...)Sen-Pieretaco Irlac, 46 gradutan, eta hiru laurden" (104/105.or.); "Halaber Sen Pieretaco Colunbia eta Miguelu portuco entrada nornoroest suduest eta dire batetic bertcera. 7. 1." (106. or.) ; "Halaber Sen Pieretaco Irlac (...)" (106. or.)

Urrunago ongi agertzen da ez dela hor dudatzerik

"Sen Pierelaco Irlen ef̧agutcecolf̧at bi Irla handi direla eta bada Irla bata bercea baino handiago ceina deitcen baita Colonbia eta baita esetican lecoa handibat Irla bañ ceina baita Irla berdea." (! 17 or.)

M. EGAÑA GOYAk dio: "Oso bixia da idazleak behin eta berriz pluralean ipinizea Pierre izen berezia." (in "XVI eta XVII mendeetako Canadako euskal leku-izenen berr", 35 or.) baina ohartzekoa da gero, $1790 / 9$ l ean Ducos Jaunaren laudorioac-etan berriz aurkitzen dugun plural hori aurki genezakeela jadanik frantsesez Jacques CARTIERen Deuxième relation-ean, 1535-36an, HOYARCABALen lana baino 25/26 urte lehenago

"Nous fumes esdictes illes sainct Pierre o'y truvames plusieurs navires tant de france que de Bretaigne depuis le jour sainct Bernabé Xle de Juin jusques au XVle jour dudit moys que appareillasmes desdictes ysles sainct ysles sainct Pierre (...)". (CARTIER.1986, 184)

Irla berdea, berriz gaurko St Pierre irlaren iparrean den irla ttipia, XVIII. mendeko frantses karta batean $I$. Verte bezala agertzen dena ez ote da horrela deitzen bakailao hezea (:-berdea) -ren lan-molde eta arrantzatzeko garaiei lotu behar delakotz? (ez du horrela pentsatzen M. EGAÑ GOYAk: "mailegu hau. batzutan ferdea bestetan berdea agertzen zen landareen koloreetatik edo irten bide da." in op. cit. 36.or.) Bakailoa hezearekin zer ikustekorik dute agian Ternuan diren bertze berde adjektibuarekin eraikiak diren toponimo batzuk : hala nola La Baye Verte, Banc a Vert etab.

Gogora dezagun bakailao hezea arrainari hertzeak kendu eta gatza botaz kontserbatzen zela, batzu bertzeen gainean metatzen zirelarik; idorrak baino gutiago balio zuen eta etzitekeen Europa hegoaldean aise kontserba.1798ko kantu bildurnari gehitu zaion $1802 \mathrm{koa}$ den Miractuilua ! Guetharian çaiçun bertso hau aurki dezakegu :

"Gure serorac arrantçaletaricljateco daude arrain fin, ederric : salesen hertceac, bacallau heceac/bide iu horratuco, guerocoac guero,astanieraiñ." (ikus URKIZU 1987, 175) 
Teknikari buruz, ikus M. EGAÑA GOYA, B. LOEWEN :

"...la technique la plus importante étail la péche sédentaire où lès pêcheurs s'établissaient sur la côte près d'un banc de morues, ils érigeaient abris et échafauds. sortaicnt quotidiennement en chaloupes pour la péche, et séchaient la monue sur les échafauds ou simplement sur la grève. (...)

La deuxième technique. le péche errante indique en quelque sorte l'adaptation de certains pêcheurs exchus des plages propices à la pèche côtière (sic). Le navire errait sur les bancs de morues, et le poisson péché était évidé sur le même navire, pour y ctre ensuite arrimé en couches intercalées de grandes quantité de sel. Le produit, appelé monue verte. ètait à la jois plus périssable et moins cher que la morue sèche.

Finalement. on pouvait retrouver une technique de péche et de livraison pratiquee en deux étapes. Comme pour la pêche errante, la morue était pêchée et évidée sur le navire. Elle étail ensuite salèe et mise en barriques pour se conserver provisoirement. Arrivees au port, les barriques étaient otvertes, le poisson rincé et remis en barriques dans une nouvelle saumure." (in "Dans le sillage des morutiers basques du Moyen Äge : une perspective...", CTHS 1995)

Ikus ere S. BARKHAM ek diona :

"Es cierto que, a partir de 1547, se realiza un mayor esfuerzo dedicado plenamente a satisfacer la demanda de "grasa" de ballena en el mercado europeo; el bacalao, mientras tanto, lo pescaban algunos miembros de la tripulación sobre todo para el consumo interior del barco. El bacalao fresco representaba una huena parte de la dieta alimenticia de los pescadores durante los meses que faenaban en Terranova, $y$ durante el viaje de regreso hubieran podido comer el bacalao "verde", es decir, salado pero no seculdo." (in Itsasoa III, 60 or.)

St Picrrc eta Miquelonekin jarraitzeko, gehi dezagun ETCHEVERRYk aipatzen duen . Misuelu, gorago aipatu 1677ko karteran den Miqueloun edo Miquelon daitekeela... Louis Armand de LOM D'ARCE LAHONTANgo baroi kaskoinak, berriz, hau zion:

"(...) Saint Pierre, l'ile Percee \& $c$ sont des ports ouvers sans forification, ni apparence d'i en pouvoir faire.", in op. cit., 1085. or.

13. P. URKIZUren ediziotik hartua da zitazione hau, J. de URQUIJOrenean aurkitzen da "Belita (?)". Aitzinago joan gabe erantsi dezagun LARRALDEeta URQUIJOren bertsioek badituztela ezberdintasunak: "Goïz portuac", "khurrucan", "hurren" (in URQUIJO/LARRALDE). Ikus ere G. ELORTZA in op. cit. 285 .

Erran beharra dago ez dela Belita izaten ahal, baizik eta Belilla edo Belila. Toponimo hau agertzen da DORREk, XVII. mendean, HOYARZABALen $1579 \mathrm{ko}$ Les voyages avantureux....-etaz egin izan zuen itzulpen/moldaketan (ikus EGAÑA-GOYA : "en ce qui concerne Terre-Neuve il ajoute toule la côte onest de l'ile"), in CTHS, 1995, 57.

DORREk, adibidez, ajpatzen ditu" Belilaco irla (cap d'Arrastic ela cap de Grateraño artean) eta Belila baya ("cap Gratetic eta Grambayaco Irletaco arrutac" jarraituz aurkitzen dena). DORREren $1677 \mathrm{ko}$ kartei edo mapei esker (ikus S. BARKHAM in Itsasoa 1987, 205,207), ikus daiteke liburuan xeheki aipatuak diren leku garrantzitsuenak ongi agertzen direla. Bi leku horiek gaur Belle lsle eta Strait of Belle Isle bezala agertzen dira kartetan (DORREren kartetan : batean Belysle, bertzean Belisle irla.)

Baina bertze Belila (Belysle DORREren kartan) bat badago, beheitiago, ipar-ekjaldean, lehen Groy irla deitzen zen irlaren ondoan. Gaurko kartetan : Bell Island eta Groais Island, biak Grey Islands deituak ere.

Beti ekialdetik baina haise hegoago, Conception Bayen badago hirugarren irla bat Bell Island bezala agertzen dena gaur baina horrela agertzen zena XVII/XVIII. mendetan (ikus LAHONTAN II.1990,1 187). DORREren kartetan ez da agertzen.

Ez da ere ahantzi behar Frantziak Quiberon aldeko itsas zabalean, Belle fle (lehengo kartetan, Belle Isle edo Bel - Isle) izeneko irla bat baduela; leku hau du J. ELORTZAk gogoan erraten duelarik: "Belila/belita (?) (L): Belle - Ile ; Bretañan ezezik, Canada aldean ere bada izen horrekin irla bat." (in Itsasoa III, 285. or.

Azken leku hau, LAHONTANgo baroiak dioenez, arras garrantzizkoa izan zen Ternuara zihoazen eta bereziki Ternuatik zetozen untziendako :

"Cette Isle [Isle d'Orleans ez mintzo da] (...) n'est que trop éloignée de France pour les vaisseaux qui en viennent, car leur traverse dure ordinairement deux mois \& demi, au lieu qu'en s'en retournant ils peuvent en trente ou quarante jours de navigation gagner aisément l'atterrage de Bel-Isle, qui est le plus seur \& le plus ordinaire des Navires au long cours." (LAHONTAN 1. 1990, 268-269).

Lau Belila baditugu beraz, hiru gaur Canadan den Ternuarenak eta bat Frantziarena. Zeintaz ari ote zaigu DUCOS jaunaren en laudorioac idarzi dituen koplakaria? Ikusiz berehala "Sn Pierrac" aipatzen dituela, Ternuan den Belila batez ari zaigu. 
14. Laukoaren gainerako bertze bi neurtitzek Ternuaren galtzea geroztik Lapurdik jasaten duen egoera latza dukete gai. Bertsu osoaren giroa arras dramatikoa da, lehendabiziko bi neurtitzek azken hatsetan diren Ternuako portuak aipatzen dituztela, heriotzaren inguruko alor semantikokoak diren aditzek erakusten dutenez ("khorrocan". "herren", "hil hurren "..) ; gainerako biek Lapurdiko egoera tristea dute aipagai, 1784eko uztailaren I4eko ordenantzaren ondotik suntsituak gelditu baitira, "franchisa'k prezioak goititiarazi zituelakotz: "Costatarrac beçala Laphurdi gucialfranchisaren azpian datça eroria."

15. "C'était le commencement de notre décadence sur le nowveau continent. Louis XIV, obligé de signer la paix, accepta les conditions de l'Angleterre. Par le traité d'Utrecht (1713), nous cédions la baie et le détroit d'Hudsow (sic). l'Acadie ou Nouvelle Ecosse ainsi que le cótes sud el est de Terre-Neuve, et la juridiction territoriale de l'île toute entière. La France conservait le privilège exclusif de la pêche sur la partie orientale des côtes, depuis le cap Bonavista jusqu'à la pointe la plus occidentale, puis, de là jusqu'au cap Riche, sur la côte ouest. Le traité interdisait à nos nationaux de fortifier aucun point à terre ou d'y ériger d'autres constructions que des cabanes de pécheurs et des échafauds nécessaires à la pêche. En outre. ils ne pouvaient séjourner dans l'île passé le temps nécessaire pour sécher la morue." (DUCÉRÉ $1893,5)$

16. Ikus CIRIQUAIN GAIZTIARRO, Los vascos en la pesca a la ballena, 302.

17. IkUS CIRIQUAIN GAIZTIARRO, in op. cit., 302-303 or.

18. Ikus M. CIRIQUAIN GAIZTIARRO, in op. cit. 303. or.

19. IkUs M. CIRIQUAIN GAIZTIARRO, in op. cit. 303-304 or.

20. Ikus 9 nota.

21. IkUS M. CIRIQUAIN GAIZTIARRO, in op. cit. 304-305.

22. Ikus M. CIRIQUAIN GAZTIARRO, in op. cit. 306-307.

23. Ikus CIRIQUIAIN GAZTIARRO in op. cil. 309 or.

24. IkUS CIRIQUAIN GAIZTIARRO in op cit 312 or.

25. Ikus $\mathrm{S}$. BARKHAM in Itsasoa $1 / I, 168,169$.

26. Ikus CIRIQUAIN GAIZTIARRO, in op. cit. 314-327.

27. XVII eta XVIII. mendeen egoeraren ideiaren ukateko, eta supran conversaren inguruan erranaren osatzeko, gogora dezagun, 1686 eta 1697 (Ryswickeko bakearekin) artean Augsburgo Ligan sartuak zirela Austria, Alemaniako printze batzu, Holanda, Ingalaterra eta Espainia, Frantziaren kontra. Garai hartan Louis XIV zelarik errege.

XVIII. mendean, berriz, jada Louis XV. menpean, supran aipatzen den Zazpi Urteko gerla 1756 tik 1763 arte iraun zuen, Frantzia, Austria eta aliatuak alderdi batean zirela eta Ingalaterra eta Prusia bertze aldean.

Lehenago Baionan 1694an izenpetu zen notario-aktan ikusten zen bezala (ikus infra, nota 9), gerla horiek sustatzen zituzten ere erregeren izenean egiten ziren ohointzak (itsas lasterrak, kurtsak) eta batek bere izenean egiten zituenak (piratakeriak) :

"Les corsaires constitutaient en quelque sorte une marine supplitive, leur action est particulièrement importante lorsque la flotte royale $n$ 'a pas la maitrise des mers, ce qui est en général le cas de la flotte royale française aux XVIIle et au XVIIIe siècle. On conçoi que dans les pays marins, comme la Breiagne et le Labourd, la guerre de course ait été importante, elle convenait particulièrement aux marins basques, rétifs à entrer dans la marine royale. Le corsaire est en somme un marin civil qui reçoil du souverain une commission pour attaquer et capturer les navires ennemis, de guerre ou de commerce. Sans aucun doute, les corsaires ont contribue par leurs prises à la prospérité du commerce de Bayonne, ils oni maintenu dans une grande mesure la richesse de St Jean de luz après la décadence de la péche. Les corsaires bayonnais se rèvèlent en 1690 avec 40 prises, puis 90 l'année suivante. De 1744 à 1782, Bayonne arma 266 navires corsaires, soit 105 pendant la Guerre de Succession d'Autriche (1744-1748), 148 pendant la Guerre de Sept Ans (1756-1761) et 13 pendant la Guerre d'Indépendance des Etats Unis (1778-1782). (..)

"Johannes de Suhigaraychipi, dit Croisic ou Coursic, est sans doute le plus célèbre des corsaires bayonnais (...). Avec Harismendy il va combattre les Hollandais au Spitzberg, ruine les installations de la baie aux Ours, fait 24 prises. Mais il meurt à Terre-Neuve où sa tombe se voyait encore récemment $\dot{a}$ 
Placentia: "Ci-git Johannes de Suhigaraychipy dit Croisic, capitaine de frégate du roi, 1694. Envieux pour l honneur de mon prince, j'allais en suivant sa carrière, altaquer les ennemis en leur mesme tanière." (...)

Plazentzako hilarriei buruz ikus 1908ko RIEVen Rdo HOWLEYk agertzen duen lana. Ikus ere M. CIRIQUAIN GAIZTIARRO in op. cit. 211-214.

E. GOYENECHEk, berriz, Lapurdiko itsas-lasterkarietaz gehitzen du

"Mais les corsaires de $S t$-Jean-de-Luz, sont justement légendaires. A vrai dire une longue tradition de piraterie les y préparait : en 1556. Haritzague, Somian. Ansogarlo, durent solliciter, pour ce motif, des Lettres Patentes de pardon. Les Luziens gagnèrent la faveur du roi quand. en 1627, avec les Bayonnais, its forcèrent le blocus de St Martin de Ré en se faufilant sur leurs pinasses et leurs flutes, tandis que Johannis de Haraneder armait, à lui tout seul, deux vaisseaux. La fin du XVIle siècle fut marquée par la génération des Chibau, Ducomte, d'Etchepare, etc. Le chevalier d'Amou. fils du bailli du Labourd, se fit corsaire et en 1692 prit 4 vaisseaux en un seul combat. Mais le plus célèbre fut Jean Peritz de Haraneder, armateur de 18 navires, qui amassa grâce en partie à la course contre les Hollandais, la fortune collossale de deux millions de livres, fut anobli par Louis XIV en 1694, deveant vicomle de Jolimomi de Haraneder, et fut la souche des vicomies de Macaye." (E. GOYENECHE, in Le Pays basque, 326-327)

28. Ikus E. GOYENECHE in op. cit. 324.or. bakailoaren arrantzaren apaltzeari buruz eta 325 na balearenari buruz.

29. Hona, bertzalde, E. GOYENECHEk zer dion :

"La morue se pêchait principalement sur le Grand Banc de Turre Neuve. On la priparait soit "verte", soit salee. La peche à la morue "verte" se pratiquait de fèvrier à fin avril. Plucentiu en était le centic. La première mention de morue pêchée par des Basques remonte à 1512 ; durant les XVIe t't XVlle siècl's ils pratiquìrent le salage et le séchage à Terre-Nèuve. Le's Basques y étaient si experts que certains furent recrutes par les Hollandais, leurs concuments. En 1635 on compte 80 navires morutiers à Saint-Jean-de Luz, 16 baleiniers et 9 moruliers à Bayonne. En 1679, à Bayonne, sur 2736 matelots, 900 sont morutiers et 760 baleiniers." (in op. cit., 324 or.).

30. Ikerketa sakonago batek eta, bereziki, ustegabeko aurkikuniza bern batek jakainarazten ahal digute hobekiago noiztsu idatziak daitezkeen

31. Erran beharra dago CHAHOk ere hiru kantu horiek kopiaru zituela. CHAHOren kopian aldakuntza ortografikoak agertzen dira. Kantu horiek ez dira nehoiz inprimatuak izan, eskerrak eman beharrak dizkiot F. ARKOTXAri eman didan kopiaz. Hona, adibidez, 1798ko bilduman den Ternuaco Penac idazkiaz (O3, artikulu honetan erabiltzen den kodigoaren arabera) zati labur bat

TERNUAKO PENAK//Untzi batzu salbaturik/ltsassoa passaturik/Arribatu Ternuarat/Behar duten Porfucturat/Ternua da mortu hotza/Eremu triste arrotza/Laboratzen ez den lurra/Neghuan bethi elurra.//(...)Ternuan dire Salbaiak/Eta Izkimaü etsaiak/Guiza bestia cruelak/Hillik jaten marinelak.//(..) Han ez da behar naghirik/fz ghezurrez den eririk/han dakite eraghiten/Alkrra fetcho eghiten.//(...) " (in A. CHAHO : Chants populaires de la Navarre et des Provinces Basques, urterik ez dakar baina 1844 baino lehenagokoa daiteke kopia. Idazki argitaragabea.).

32. Hizki ilunez agertzen dira A, B, C agerkarietan diren aldakuntzak; ortografikoak : letra larri edo ttipien aldatzeak, adibidez "Beguiz", "beguiz" zelarik; "u"ren gehitze, orduan azpimarratzen delarik silaba osoa, adibidez "gi", jatorrizko testua "gui" zelarik) ; gaizki ulertuak diren hitzak, adibidez "digula", "diçula"ren ordez; eta ere transkribitzaileak berak, kasu honetan Elortzak, zalantza bat badela galdera markatuz erakusten duelarik, adibidez "bezain (?)". 


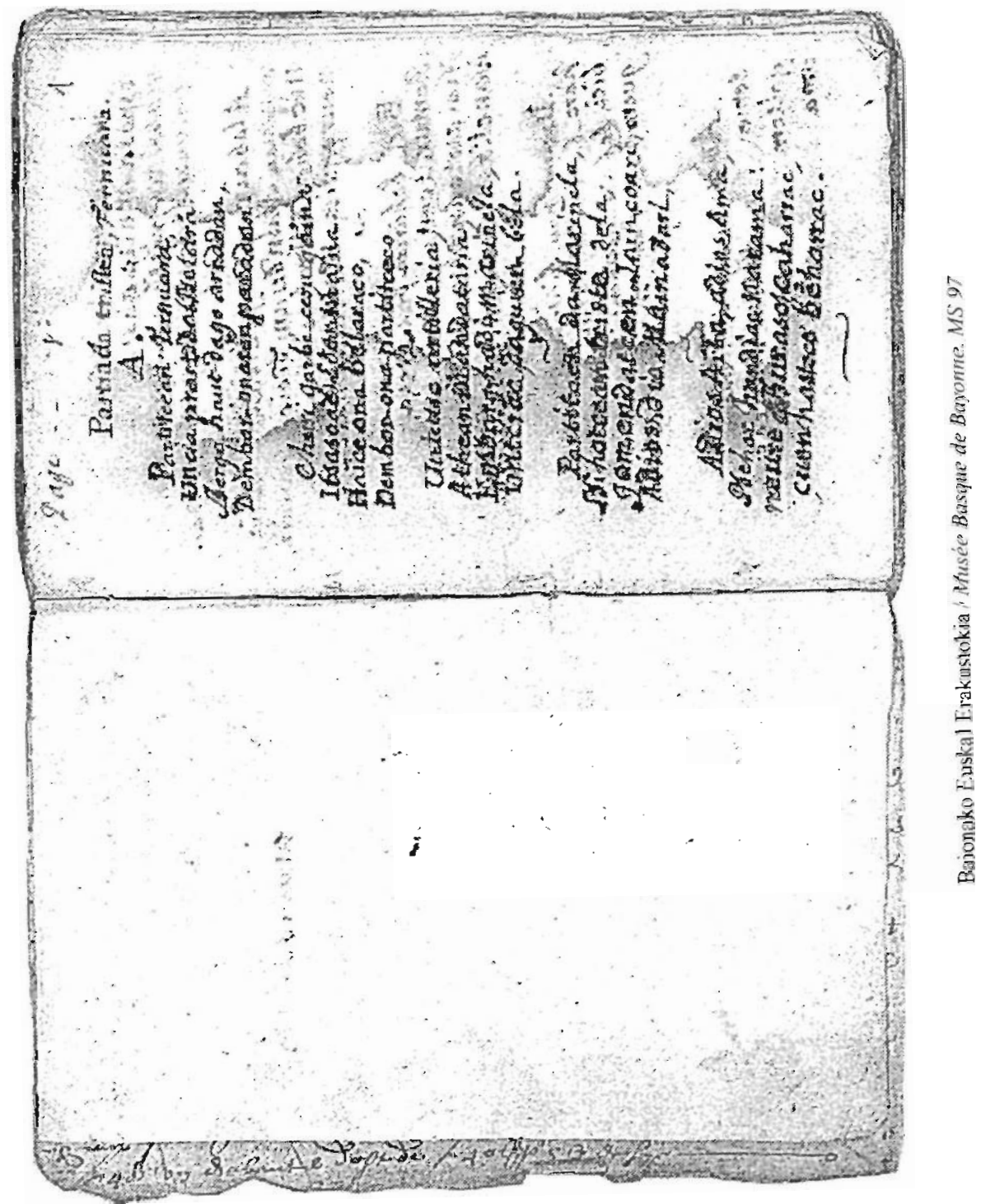




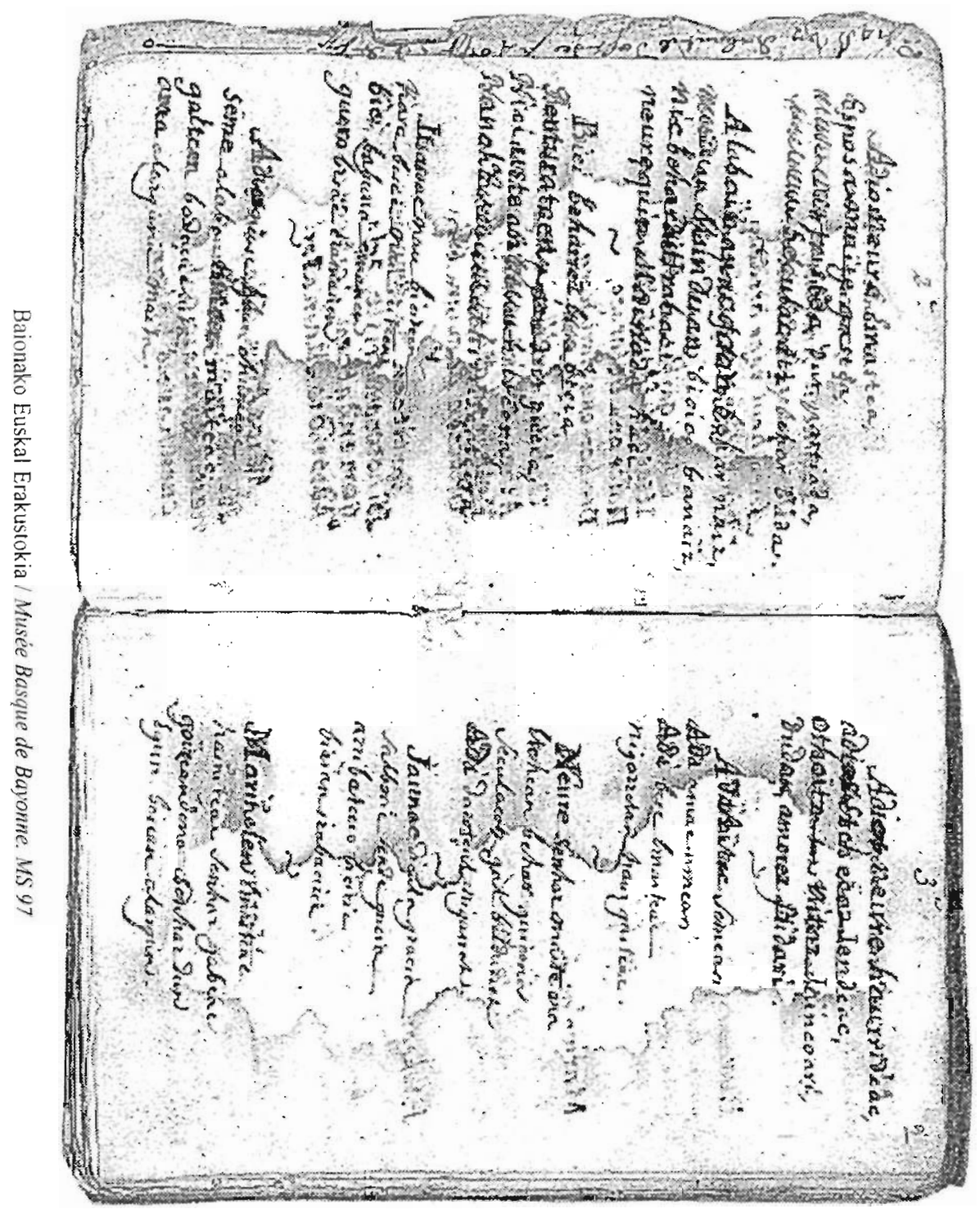




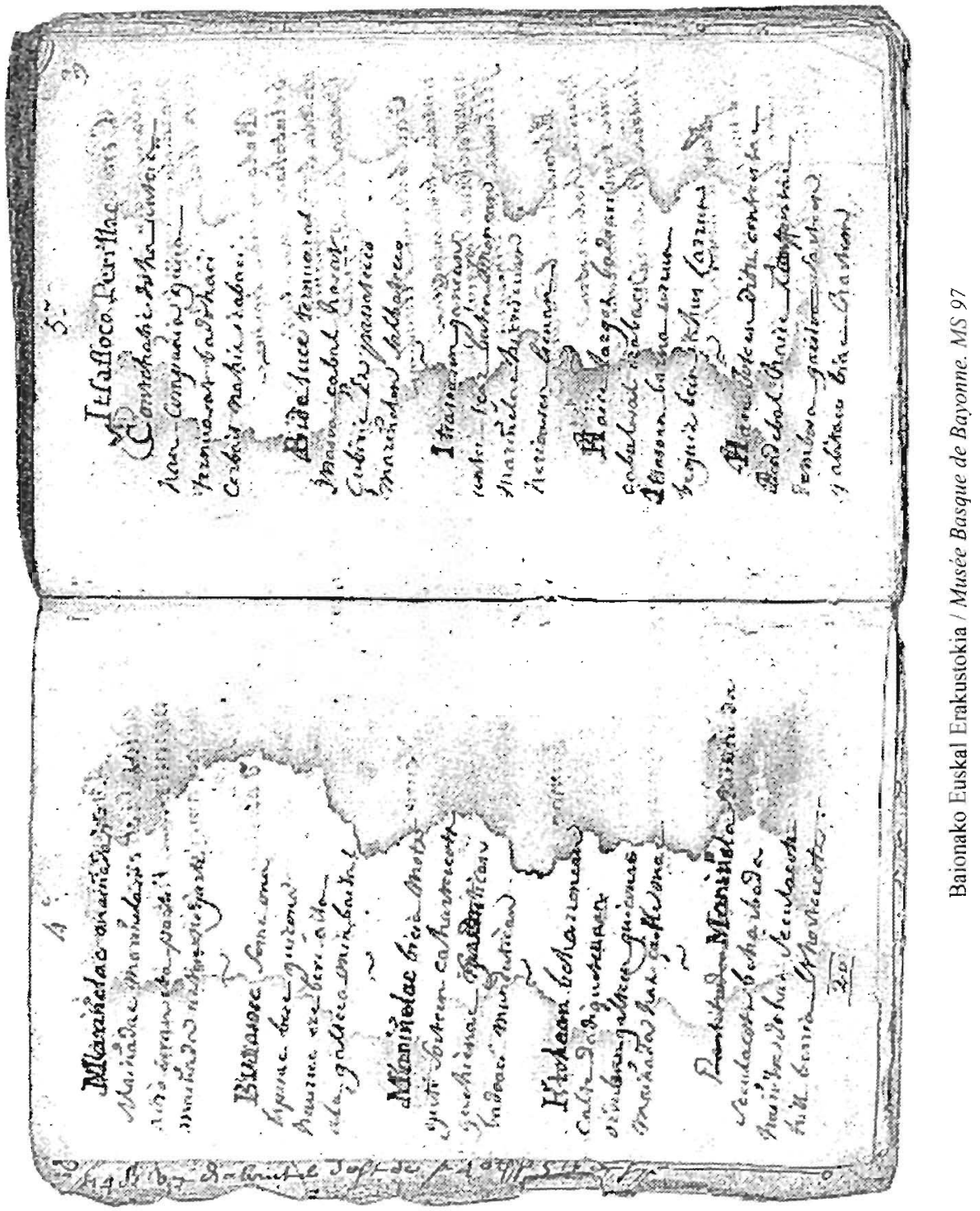




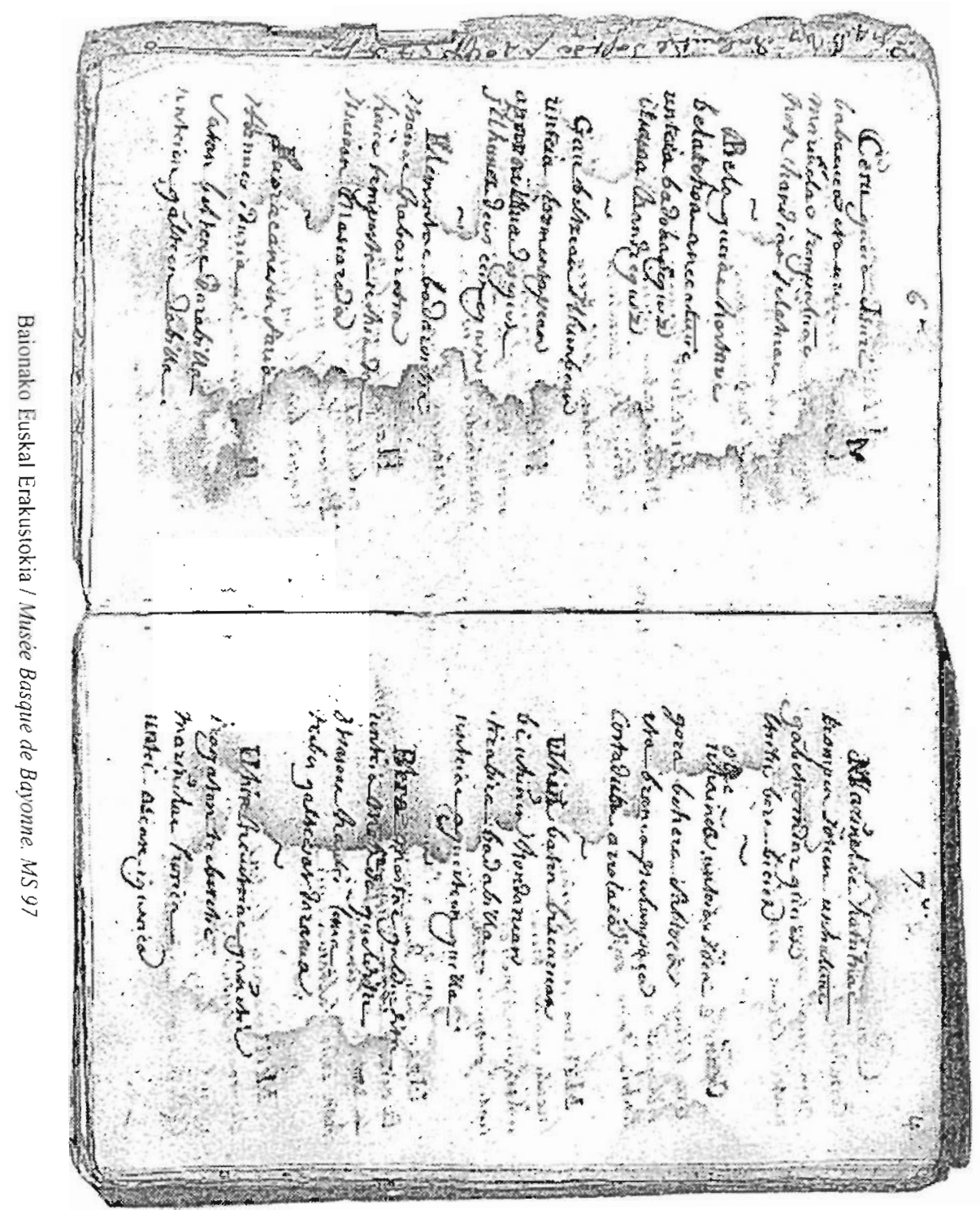




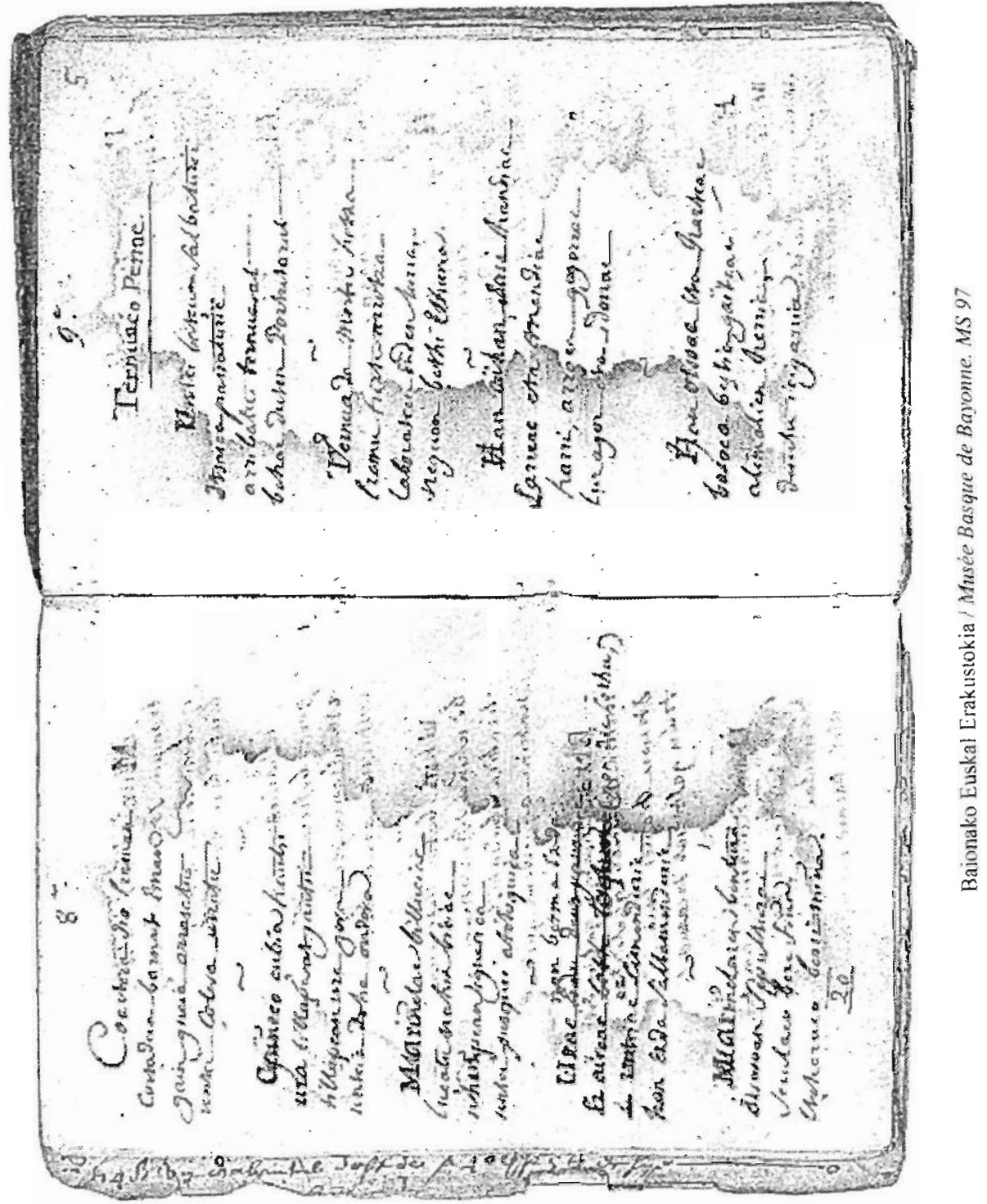




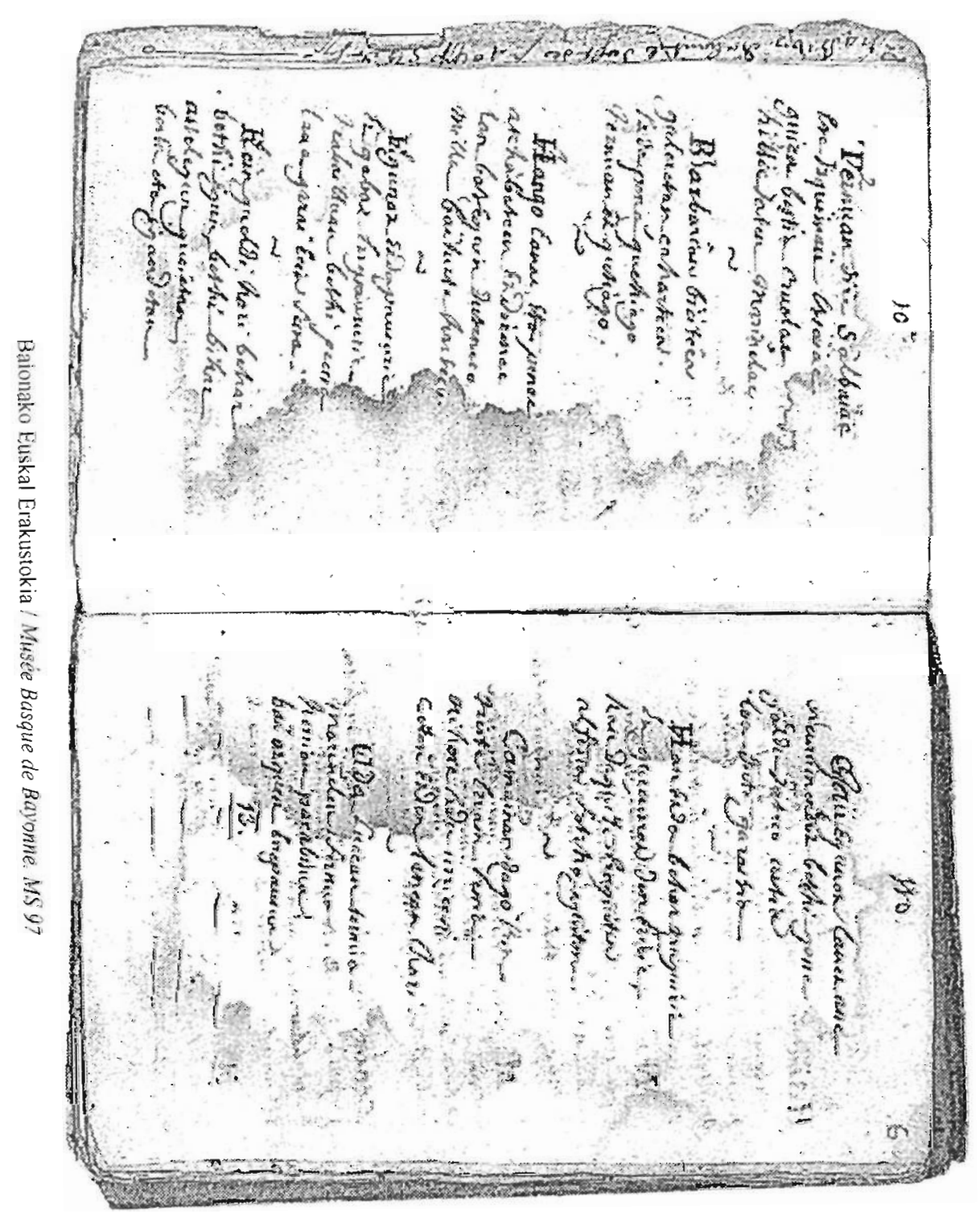




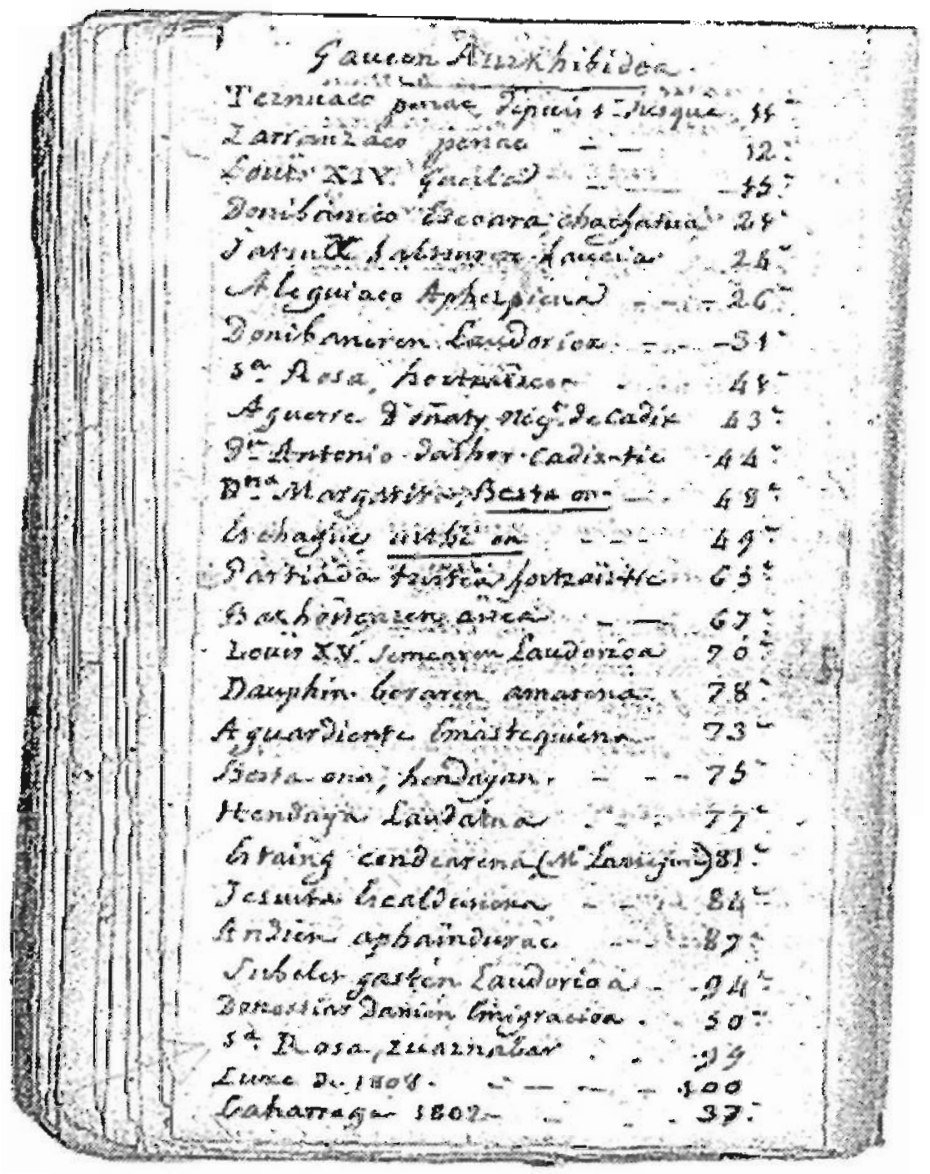

